\title{
Pemodelan dan Pembuatan Peta Evakuasi Tsunami Pesisir Sanur
}

\author{
I Putu Dedy Pratama*1
}

${ }^{1}$ BMKG Stasiun Geofisika Denpasar, Denpasar, Indonesia

\author{
A R T I C L E I N F O \\ Article history: \\ Received 26 January 2020 \\ Received in revised form 29 \\ April 2020 \\ Accepted 07 July 2020 \\ Available online 31 August \\ 2020
Kata Kunci:
Peta evakuasi
Keywords:
Sanur; Tsunami;
Inundation; Evacuation
maps \\ Sanur; Tsunami; Inundasi;
}

\begin{abstract}
A B S T R A K
Garis pantai Sanur yang panjang dan padatnya aktivitas pariwisata menjadi perhatian agar perlu adanya pembuatan peta evakuasi tsunami. Peta evakuasi yang sudah ada perlu diperbaharui karena PuSGeN menyatakan potensi gempabumi maksimum oleh Megathrust selatan bali mencapai M7,8 kemudian pada tahun 2017 dilakukan permutakhiran menjadi M9,0. Pemodelan inundasi tsunami digunakan untuk memperkirakan dampak tsunami terburuk. Pemodelan dilakukan menggunakan ComMIT menggunakan gabungan skenario M9,0 dan tsunami Banyuwangi 2 Juni 1994, kemudian untuk data topografi menggunakan SRTM dan batimetri dari ETOPO1. Enam titik virtual tide gauge dibuat untuk melihat karakter gelombang tsunami di sepanjang pantai Sanur. Hasil pemodelan inundasi tsunami yaitu jarak inundasi bervariasi antara $2-3 \mathrm{~km}$ ke arah darat, ketinggian tsunami di pantai bervariasi antara 9,9 hingga 16,8 meter dengan run-up maksimum 21 meter, dan waktu tiba tsunami di pantai sekitar 24 menit setelah gempabumi terjadi.
\end{abstract}

\section{A B S T R A C T}

Sanur's coastline is long and crowded tourist activities which need to be considered making tsunami evacuation maps. Existing evacuation maps need to be approved because PuSGeN states that the maximum earthquake potential by Megathrust south of Bali reaches M7.8 then in 2017 an update was changed to M9.0. Tsunami inundation modeling was used for worst case tsunami estimation. Modeling was carried out using ComMIT with combination of the M9.0 scenario and the Banyuwangi tsunami of 2 June 1994, then for topographic data using SRT M and bathymetry from ETOP01. Six virtual tide gauge locations were set to detect wave characteristics of the tsunami along the coast of Sanur. The results showed that the inundation distance varied from 2-3 kilometers inland, the tsunami wave height varied from 9,9 to 16,8 meters with maximum run up 21 meters, and tsunami arrived at coastal area within 24 minutes after the earthquake.

\footnotetext{
* Corresponding author.

E-mail addresses: checkmate.mail1@gmail.com
} 


\section{Pendahuluan}

Sanur merupakan wilayah di Kota Denpasar yang memiliki kerentanan terhadap tsunami. Garis pantai yang panjang dan padatnya aktivitas pariwisata di daerah ini menjadi perhatian agar perlu adanya pembuatan peta evakuasi tsunami.

Sanur sudah memiliki rencana evakuasi yang sangat baik (Kelompok Kerja Perencanaan Evakuasi Untuk Sanur, 2010). Tsunami drill juga sudah pernah dilaksanakan pada 26 Desember 2006. Tsunami drill kurang lebih 1000 orang peserta dari 10 Desa di Denpasar Selatan dan merupakan tsunami drill terbesar di Bali hingga saat ini. Sejak tahun 2009 sirine tsunami sudah terpasang di pantai Matahari Terbit memiliki jangkauan bunyi dengan radius mencapai $1 \mathrm{~km}$. Sirine dilakukan tes bersama dengan 8 sirine lainnya di wilayah Bali setiap bulan pada tanggal 26 pukul 10:00 WITA.

Peta inundasi tsunami sudah dibuat oleh Badan Geologi pada tahun 2007. Hal ini yang dijadikan acuan Pemerintah Provinsi Bali dalam melakukan pengkajian bahaya tsunami bekerja sama dengan GIZ dalam membuat peta bahaya, peta risiko, dan peta evakuasi lengkap beserta dokumentasi teknisnya.

Berdasarkan Pusat Studi Gempa Nasional (PuSGeN) tahun 2017 potensi gempabumi maksimum untuk selatan Bali disebabkan oleh megathrust segmen Bali mencapai M9,0 (Tim Pusat Studi Gempa Nasional, 2017). Awalnya pada potensi gempabumi maksimum oleh Megathrust selatan bali mencapai M7,8 kemudian pada tahun 2017 dilakukan permutakhiran menjadi M9,0 (Gambar 1).

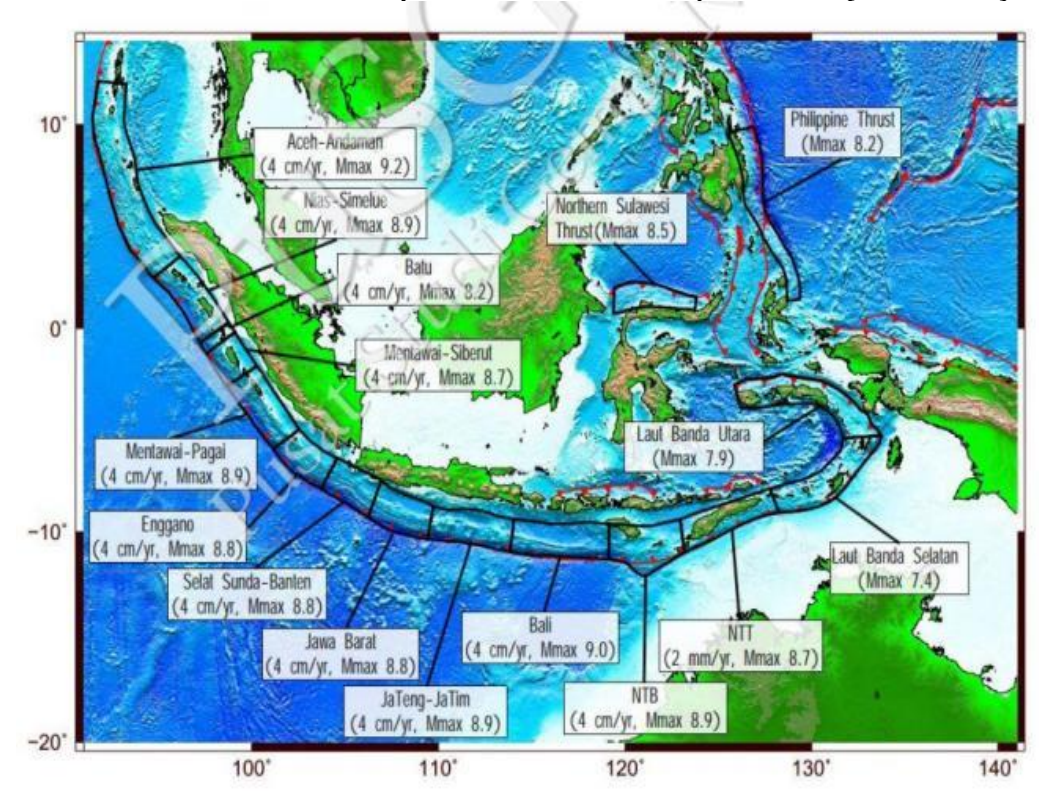

Gambar 1. Permutakhiran Segmentasi Megathrust Peta Gempa Nasional 2017 (Tim Pusat Studi Gempa Nasional, 2017)

Menurut buku Katalog Tsunami Indonesia 416-2017 (Tim Pusat Gempabumi dan Tsunami, 2019), kejadian gempabumi besar dan tsunami besar yang pernah berdampak di selatan Pulau Bali ada 2 yaitu gempabumi dan tsunami Banyuwangi 2 Juni 1994 dan tsunami Sumba 19 Agustus 1977. Gempabumi Banyuwangi M7,8 menimbulkan tsunami dengan run-up tertinggi 13,9 meter di Rejakwesi-Banyuwangi. Untuk Pulau Bali catatan run-up tertinggi di pantai Antap-Tabanan 4,1 meter, di Pantai Soka-Jembrana 3,7 meter, Klating-Tabanan 3,5 meter, Pekutatan-Jembrana 2,8 meter, Rambut Siwi-Jembrana 2,7 meter, Tanah Lot-Tabanan <2 meter dan Pantai Kuta 1 meter. Tidak terdapat catatan tsunami di wilayah Denpasar. Namun, menurut penuturan penduduk setempat terjadi pasang air laut dengan inundasi sekitar 5 meter dari pantai. Gempabumi Sumba M8,0 dengan run-up tertinggi di Sumba setinggi 3 meter. Untuk Pulau Bali tsunami terjadi di Pantai Kuta menewaskan 1 orang dan 3 orang hilang, Pantai Sanur gelombang menyapu helipad, menenggelamkan toko pinggir pantai, dan merusak perahu serta korban seratus nelayan luka berat, Tsunami Sumba juga tercatat di Nusa Penida yang melongsorkan pantai sepanjang 25 meter dan menimbulkan gelombang pasang puluhan meter. Informasi tsunami Sumba memiliki keanehan karena catatan run-up wilayah terdekat hanya mencapai 3 meter sedangkan di Nusa Penida mencapai puluhan meter tidak sesuai dengan teori yang ada. Hal ini karena informasi sebatas pengalaman masyarakat yang bersifat subjektif.

Daerah Sanur memiliki dataran rendah pantai, sungai, dan rawa dengan kemiringan 0-2 meter di atas permukaan laut. Selain itu, itu beberapa bagian wilayah Sanur merupakan daerah bergelombang dengan kemiringan 2 - 8\% (Widiyani, 2014). Wilayah yang landai dan ketinggian yang rendah membuat Sanur rentan terhadap tsunami. Untuk itu diperlukan kajian pembuatan peta evakuasi tsunami. 
Permutahiran peta evakuasi tsunami yang sudah ada perlu dilakukan karena adanya perubahan hasil kajian potensi gempabumi di selatan Bali. Selain itu, peta yang sudah ada dibuat pada tahun 2010 perlu dilakukan perbaikan mengingat adanya perubahan infrastruktur dan jalur evakuasi yang baru tentunya juga penguatan rantai informasi, peran, dan tanggung jawab setiap institusi dalam proses evakuasi tsunami.

\section{Metode}

Alur pengolahan data (Gambar 2) menggunakan data masukan yang bersumber dari data katalog tsunami selatan Bali berdasarkan sejarah tsunami yang pernah terjadi (Tim Pusat Gempabumi dan Tsunami, 2019). Karena keterbatasan data katalog, perlu memperhatikan potensi Megathrust selatan Bali (Tim Pusat Studi Gempa Nasional, 2017). Kemudian, untuk pemodelan menggunakan data topografi Shuttle Radar Topography Mission (SRTM) dengan resolusi 90 meter (Reuter, Nelson, dan Jarvis, 2007) dan batimetri ETOP01 dengan resolusi 1 menit busur atau setara dengan 1,8 km (Amante dan Eakins, 2009). Parameter sesar yang berpengaruh besar terhadap ketinggian run-up tsunami yaitu parameter dip, slip (Wahyu, dkk., 2018) dimana parameter sesar yang mendominasi di selatan Bali adalah sesar naik dengan dip landai atau kurang dari 45 derajat (Global CMT, 2020). Parameter ini masukan dalam grid yang ditentukan sebagai batasan wilayah pemodelan (Gambar 3).

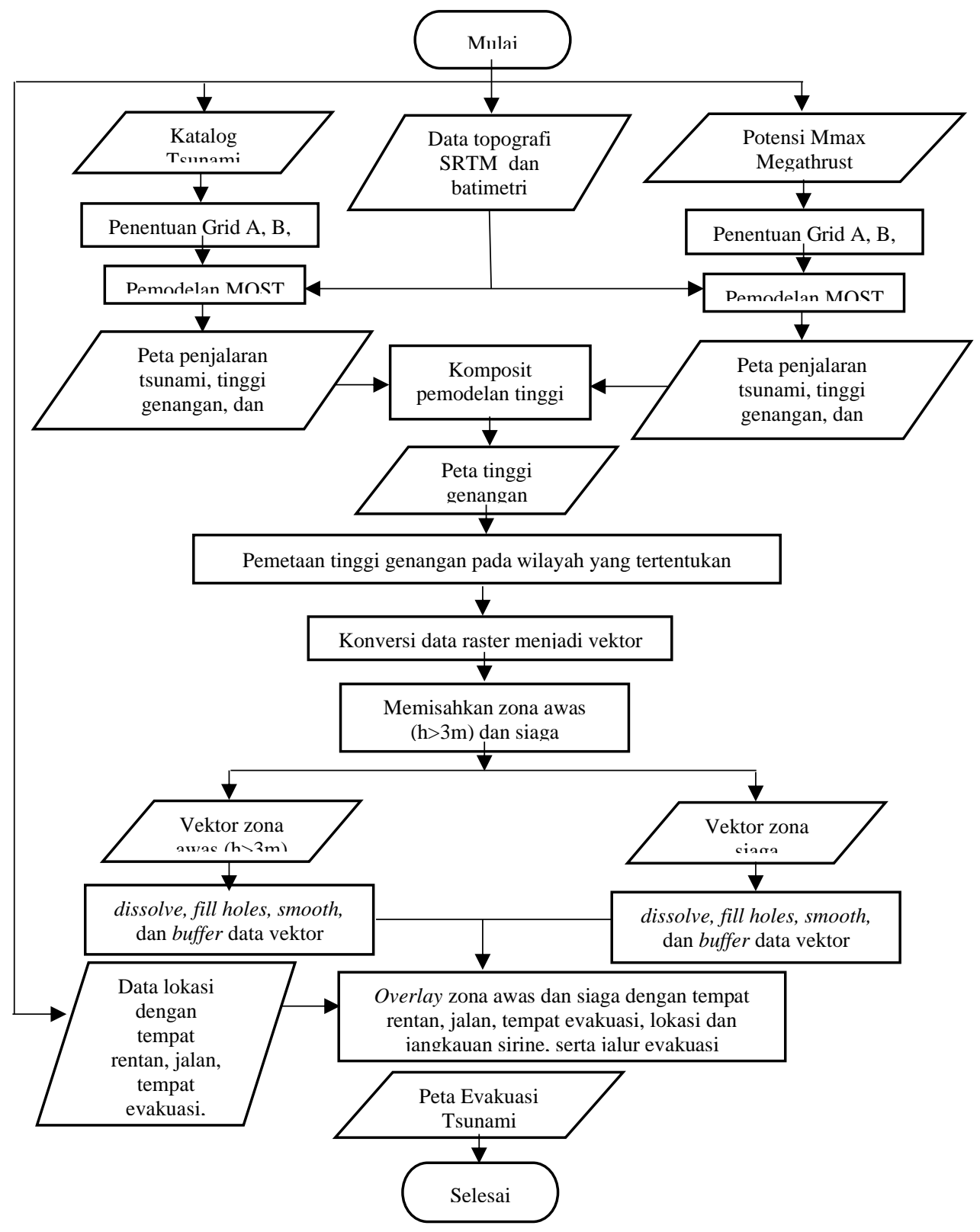

Gambar 2. Diagram alir pengolahan data 

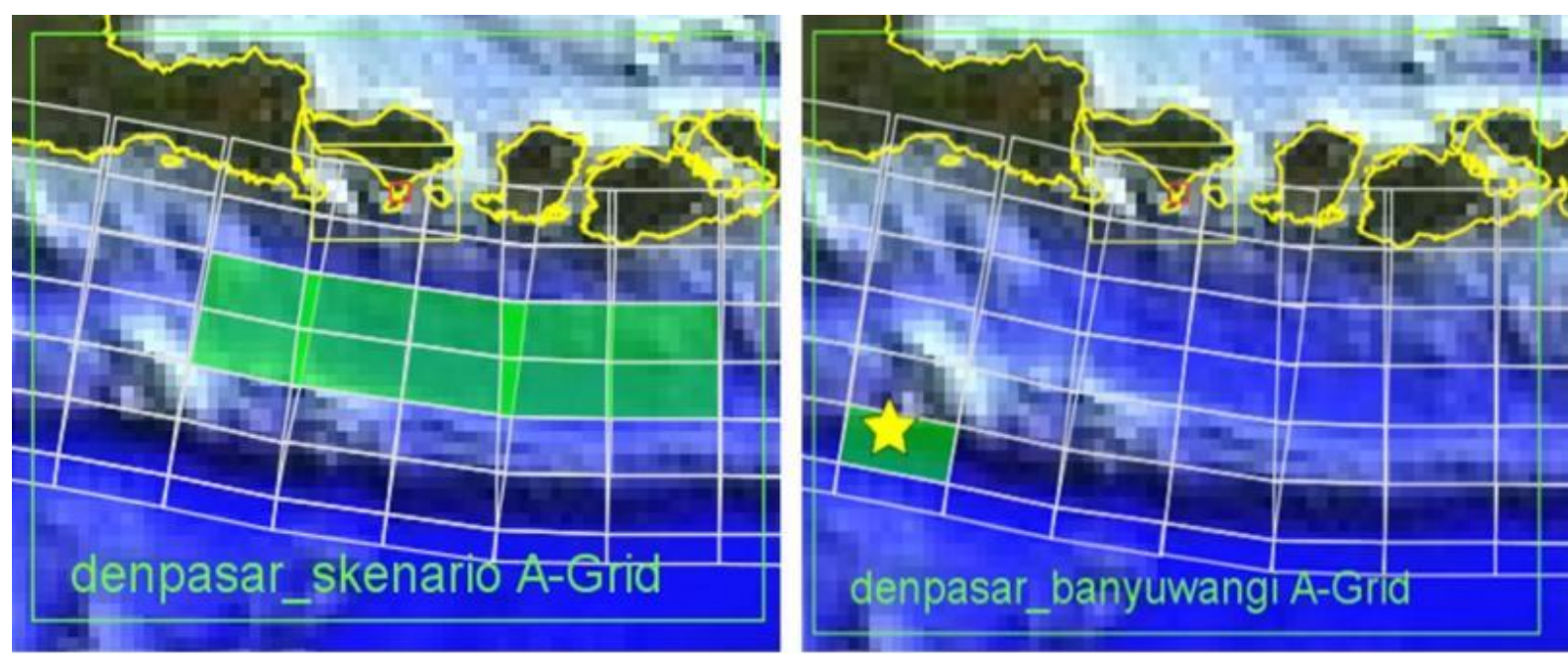

Gambar 3. Segmen sesar yang digunakan dalam skenario tsunami Mmax 9,0 (kiri) dan tsunami Banyuwangi 1994 (kanan) serta grid pemodelan tsunami.

Jika dilihat dari Gambar 3, diperlukan 10 segmen untuk membuat gempabumi dengan magnitudo 9 dari gempabumi dengan magnitudo 7,8. Penentuan segmen skenario dibuat berdasarkan lokasi gempabumi dengan kedalaman dangkal yang berada dekat dengan pantai Sanur. Penentuan grid A, B, dan C dibuat berdasarkan kemudahan dalam membuat kualitas hasil pemodelan dan animasi dimana mencakup wilayah sumber gempabumi dan lokasi pemodelan inundasi. Tsunami Sumba tidak dilibatkan dalam perhitungan karena sudah digantikan dengan skenario dengan azimuth yang sama namun magnitudo lebih besar.

Untuk membuat perkiraan genangan tsunami dilakukan pemodelan tsunami dengan MOST. Sistem MOST dijalankan menggunakan aplikasi ComMIT (COMmunity Model Interface for Tsunami). ComMIT merupakan antarmuka berbasis internet untuk model tsunami komunitas yang dikembangkan oleh Pusat Penelitian Tsunami (NCTR) NOAA (Titov, dkk., 2011).

Analisis kestabilan model numerik yang dijalankan. Oleh karena itu digunakan kondisi CourantFriedrichs-Lewy (CFL) agar model numerik yang dijalankan menjadi stabil. Kondisi stabilitas CFL dapat dicapai dengan memilih ukuran grid dan langkah waktu yang sesuai (Courant, Friedrichs, dan Lewy, 1967). Kondisi CFL dapat dicapai apabila :

$$
\Delta t \leq \frac{\Delta x}{\sqrt{2 g d}}
$$

dimana $\Delta \mathrm{x}$ adalah ukuran spasial grid, g adalah tetapan gravitasi dan $\mathrm{d}$ adalah kedalaman atau batimetri lautan. Persamaan ini menjelaskan bahwa langkah waktu $(\Delta t)$ harus sama dengan atau lebih kecil dari waktu yang diperlukan gelombang untuk menjalar sejauh ukuran spasial grid $(\Delta \mathrm{x})$.

Pemodelan tsunami (baik propagasi dari laut dalam maupun genangan) memerlukan informasi tentang: (1) batimetri dasar laut dan topografi pantai; (2) kondisi awal dan batasan wilayah; dan, (3) pemodelan menjalankan informasi spesifik seperti langkah-waktu, resolusi spasial, dan lama menjalankan model. Tujuan dari ComMIT adalah untuk menyediakan antarmuka yang memungkinkan pemilihan data input model (kondisi awal, grid batimetri, dll.) ComMIT telah ditulis dalam bahasa pemrograman Java (versi 1.5) dan menggunakan format NetCDF untuk input dan output model sehingga membuat platform ComMIT independen (misal dapat dijalankan pada platform yang berbeda seperti MS WINDOWS, MAC OS atau UNIX). ComMIT dapat digunakan dengan model komputasi yang berbeda (atau kombinasi model) dengan persyaratan bahwa model tersebut dapat memasukkan dan mengeluarkan data dalam format tertentu (kebanyakan format NetCDF - format jaringan Data Umum (UNIDATA, 2019)), dan parameter input untuk model dibaca dari file teks sederhana (ASCII). Penggunaan format NetCDF yang dikecualikan secara universal dan terstandar memberikan akses ke sejumlah perangkat lunak sumber terbuka untuk presentasi dan analisis data model. Saat ini, model MOST diimplementasikan untuk bekerja dengan antarmuka.

Pemetaan dibuat dengan menggunakan aplikasi QGIS versi 2.18 Las Palmas. Dengan memanfaatkan data raster hasil dari pemodelan ComMIT, sehingga diperoleh data daerah terdampak yang kemudian dioverlay dengan data peta dasar. Analisis overlay menggunakan data objek vital seperti hotel berlantai 2 ke 
atas dan kantor pemerintah untuk tempat evakuasi sementara, sekolah dan pasar sebagai objek rentan tsunami, puskesmas dan klinik untuk memperoleh bantuan medis, dan sirine beserta jangkauan sebagai informasi mitigasi. Selanjutnya ditentukan arah jalur evakuasi berdasarkan jalan di wilayah Sanur yang disesuaikan dengan hasil daerah terdampak.

\section{Hasil dan pembahasan}

Dari pengolahan data diperoleh hasil berupa animasi tsunami (Gambar 4 dan 5). Cuplikan animasi difokuskan pada animasi saat gelombang pertama kali mencapai pesisir Sanur dan pada kondisi inundasi terluasnya. Dapat dilihat pada Gambar 4 bahwa pemodelan tsunami Banyuwangi 1994 menunjukan bahwa gelombang pertama kali tiba di pesisir pantai Semawang 43 menit setelah gempabumi. Untuk inundasi maksimum pada menit ke 52 tidak terlihat jelas karena gelombang tidak mencapai jarak lebih dari 100 m dari pesisir pantai.
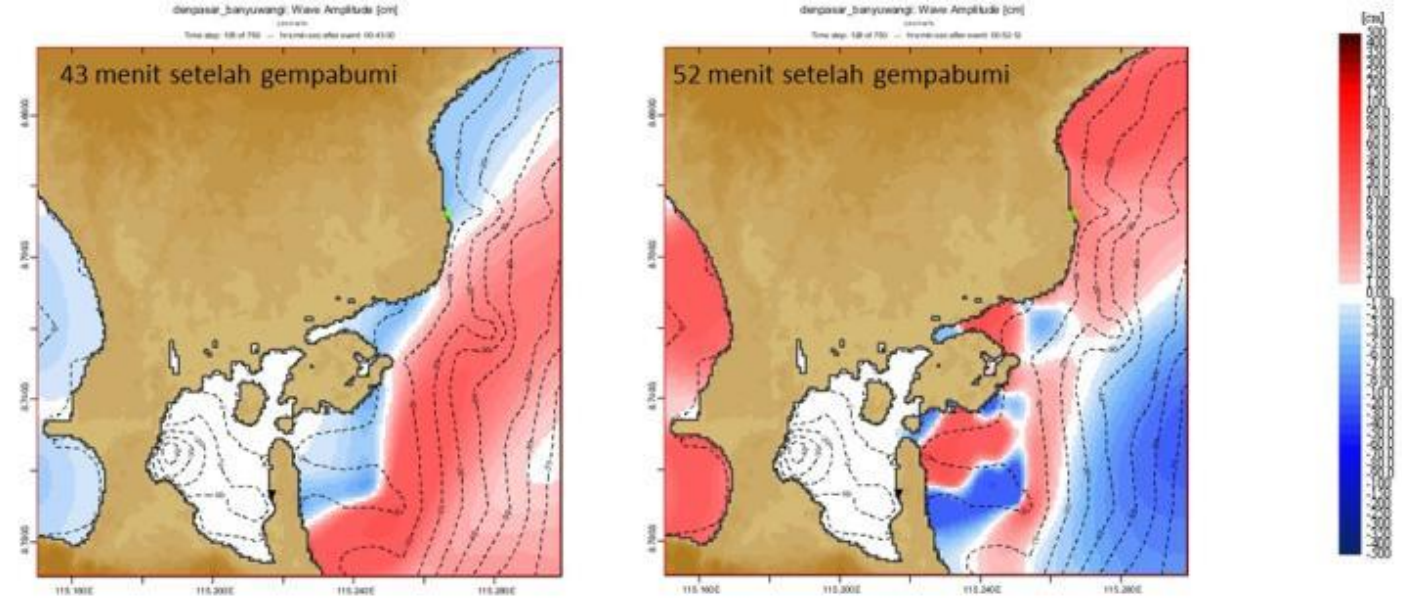

Gambar 4. Cuplikan animasi pemodelan tsunami Banyuwangi 1994 saat pertama kali mencapai pesisir Sanur (kiri) dan saat mencapai inundasi maksimum (kanan)

Untuk pemodelan tsunami dengan skenario gempabumi dengan Mmax 9,0 di selatan Bali (Gambar 5) menunjukan bahwa gelombang tsunami juga pertama kali tiba di pesisir Semawang 24 menit setelah gempabumi. Waktu tiba yang lebih singkat untuk hasil skenario karena sumber gempabumi berada lebih dekat dengan pesisir Sanur. Dalam waktu 39 menit tsunami sudah menggenangi seluruh wilayah Sanur.
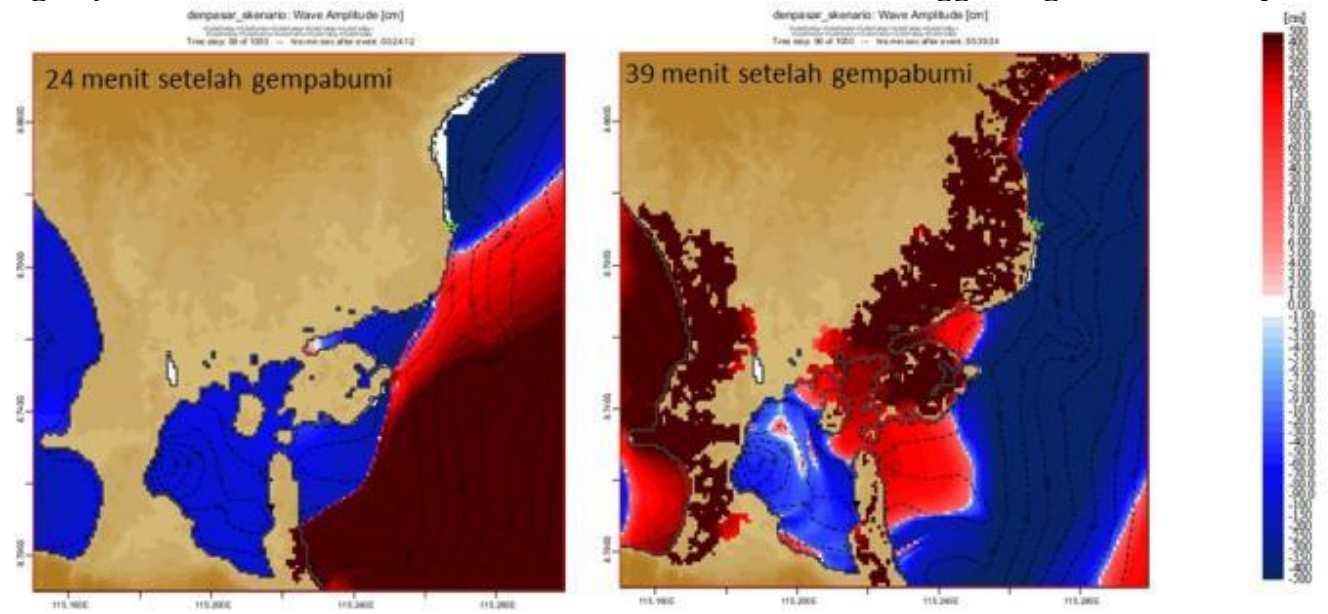

Gambar 5. Cuplikan animasi pemodelan tsunami dengan skenario gempabumi dengan Mmax 9,0 saat pertama kali mencapai pesisir Sanur (kiri) dan saat mencapai inundasi maksimum (kanan) 


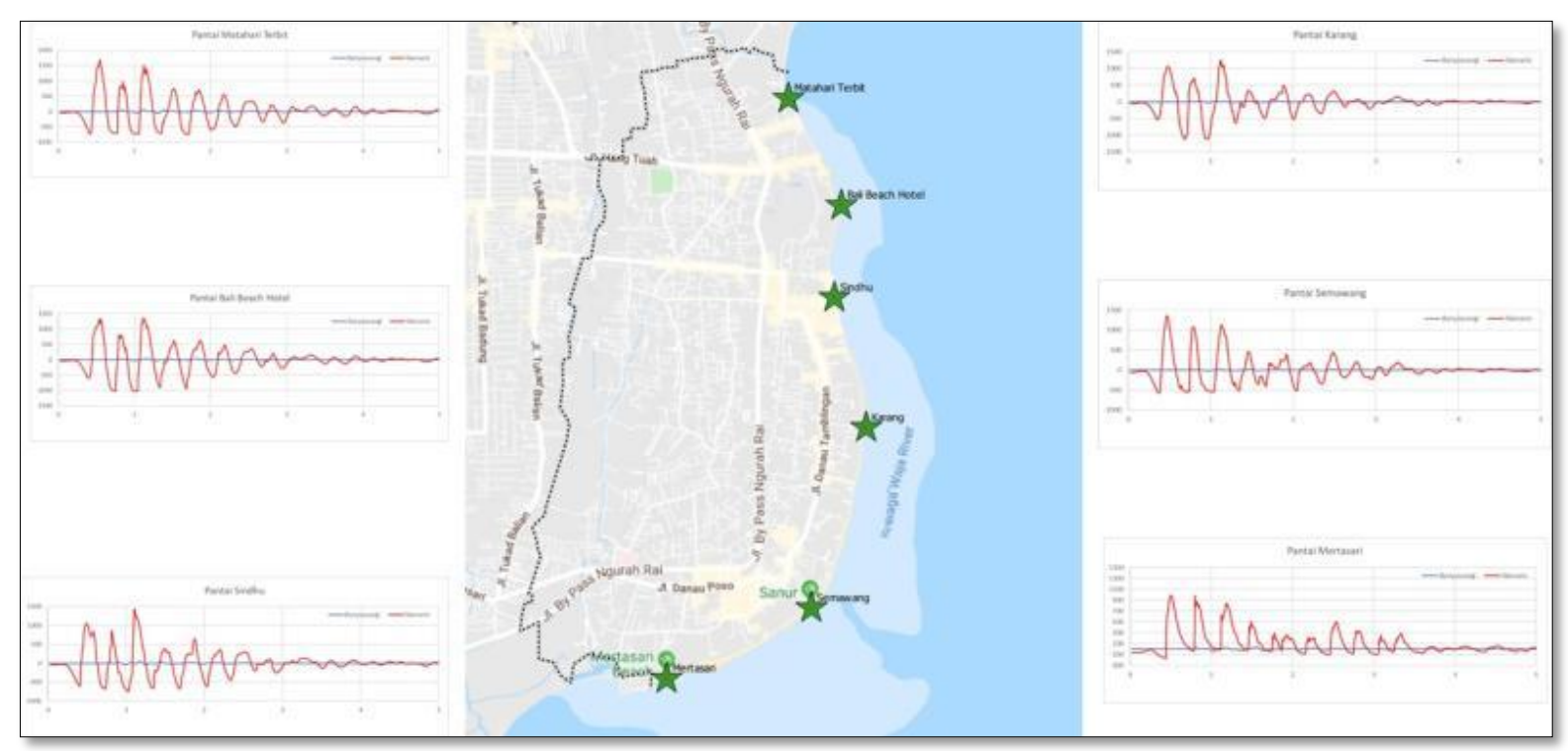

Gambar 6. Model komposit perbandingan ketinggian gelombang tsunami akibat gempabumi Banyuwangi 1994 dan skenario gempabumi Mmax 9,0 di selatan Bali

Berdasarkan hasil pemodelan komposit tsunami Banyuwangi dan skenario gempabumi selatan Bali Mmax 9,0 dibuat grafik ketinggian gelombang untuk enam pantai di wilayah Sanur (Gambar 6). Enam lokasi tersebut diasumsikan memiliki tide gauge untuk mendeteksi ketinggian gelombang di pesisir pantai. Hasil pemodelan menghasilkan ketinggian tsunami maksimum akibat tsunami Banyuwangi 1994 untuk pesisir Sanur tertinggi terjadi di Pantai Matahari Terbit dengan ketinggian $48 \mathrm{~cm}$. Pemodelan menunjukan tsunami tiba pertama kali di Pantai Semawang yang berselisih 42 menit setelah terjadi gempabumi dengan didahului oleh air surut pada 12 menit setelah gempabumi terjadi. Untuk tsunami skenario gempabumi selatan Bali Mmax 9,0 menunjukan hasil yang berbeda signifikan dengan tsunami Banyuwangi 1994. Ketinggian maksimum mencapai 21 meter di utara Pantai Matahari Terbit. Pemodelan menunjukan tsunami tiba pertama kali di Pantai Semawang yang berselisih 24 menit setelah terjadi gempabumi dengan didahului oleh air surut pada 16 menit setelah gempabumi terjadi. Hal ini sesuai dengan penelitian Purnama, dkk. (2019) yang menyatakan ketinggian maksimum tsunami di Sanur mencapai di atas 18 meter.

Akurasi dari pemodelan tsunami dalam membuat peta inundasi berhubungan erat dengan bathimetri dan topografi yang digunakan. Menggunakan data resolusi tinggi mampu meningkatkan akurasi namun memerlukan banyak waktu dalam pemrosesan data (Delavar, dkk., 2017).

Pada Gambar 7 keseluruhan pemodelan menunjukan pola yang cenderung mirip baik tsunami Banyuwangi 1994 maupun skenario Mmax 9,0. Untuk tsunami Banyuwangi surutnya air laut tidak terjadi signifikan jika dibandingkan dengan ketinggian tsunaminya, sedangkan pada hasil skenario Mmax 9,0 menunjukan adanya air surut signifikan sebelum tsunami besar terjadi. Pemodelan tsunami Banyuwangi 1994 terjadi gelombang tsunami dengan gelombang yang lebih rendah kemudian disusul gelombang dengan ketinggian maksimum. Pada pemodelan skenario Mmax 9,0 setelah air laut surut maka ketinggian tsunami maksimum tiba di pesisir. Kondisi seperti tsunami Banyuwangi 1994 patut diwaspadai karena setelah gelombang pasang tsunami datang masih ada potensi gelombang yang lebih besar datang setelahnya. Dari kedua hasil simulasi pemodelan menunjukan bahwa amplitudo awal surut gelombang lebih kecil daripada amplitudo pasangnya. 


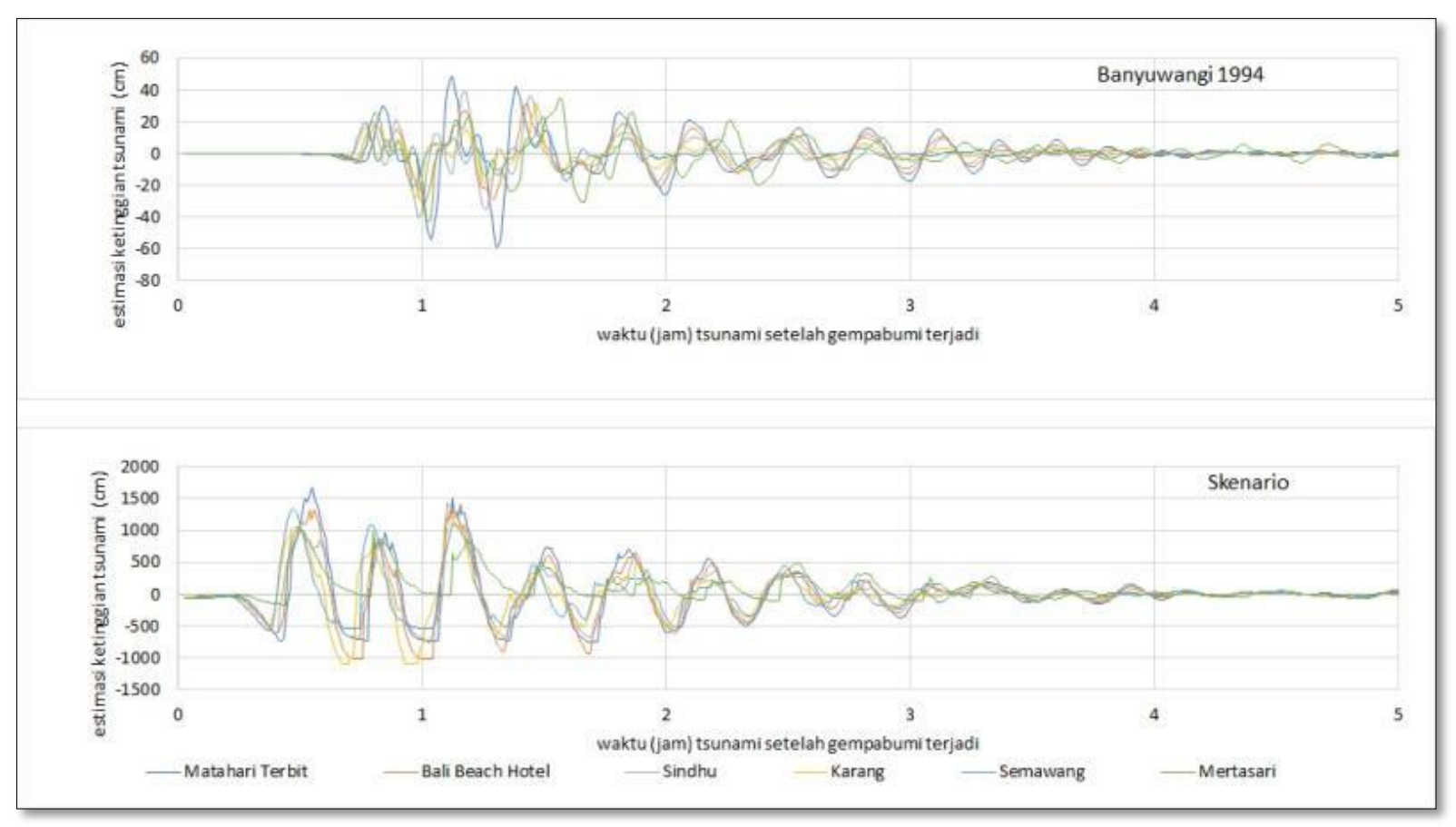

Gambar 7. Grafik perbandingan ketinggian gelombang tsunami akibat gempabumi Banyuwangi 1994 (atas) dan skenario gempabumi Mmax 9,0 di selatan Bali (bawah)

Hasil pengolahan data komposit Sanur (Gambar 8), keseluruhan wilayah Sanur baik Sanur Kauh, Sanur Kaja, dan Kelurahan Sanur berada dalam zona awas. Run up tertinggi mencapai 21 meter di utara Pantai Matahari Terbit. Hal ini karena bentuk teluk yang menyebabkan gelombang tsunami terkumpul di lengkungan garis pantainya. Adanya teluk membuat gelombang berkumpul dan saling terpantul saat mencapai daratan sehingga terjadi amplifikasi gelombang (Nurfitriani, dkk., 2018). Untuk pantai Matahari Terbit, Bali Beach Hotel, Sindhu, Semawang, dan Mertasari ketinggian tsunami berturut-turut 16,8 meter, 13,6 meter, 14,3 meter, 12,3 meter, 13,5 meter, dan 9,9 meter. Ketinggian tsunami lebih rendah di Pantai Bali Beach Hotel dan Karang dibandingkan dengan Sindhu karena daratannya berupa semenanjung. Sedangkan untuk Pantai Mertasari karena pantainya menghadap ke selatan dan gelombang tsunami dari selatan sudah terhalang oleh daratan di Jimbaran dan Serangan.

Hampir keseluruhan wilayah Sanur tergenang tsunami pada skenario terburuknya dengan ketinggian genangan lebih dari 3 meter. Hal ini menunjukan jika terjadi gempabumi dengan potensi tsunami pada level awas evakuasi menyeluruh sangat diperlukan. Magnitudo gempabumi sangat mempengaruhi run up tsunami. Hal ini disebabkan oleh semakin besarnya nilai magnitudo momen dan semakin luas bidang sesar gempa bumi sehingga magnitudo semakin besar. Nilai run up juga dipengaruhi oleh kondisi batimetri, nilai run up tsunami akan meningkat pada kondisi batimetri perairan laut dangkal dan memiliki teluk (Aperus, Pujiastuti, dan Billiyanto, 2016).

Tsunami yang terjadi di Sanur bagian selatan memiliki jarak inundasi dari pesisir pantai yang lebih jauh ke daratan jika dibandingkan dengan Sanur bagian timur. Hal ini karena wilayah selatan topografinya lebih landai dan adanya Tukad Loloan yang menjadi jalan aliran tsunami ke daratan. 


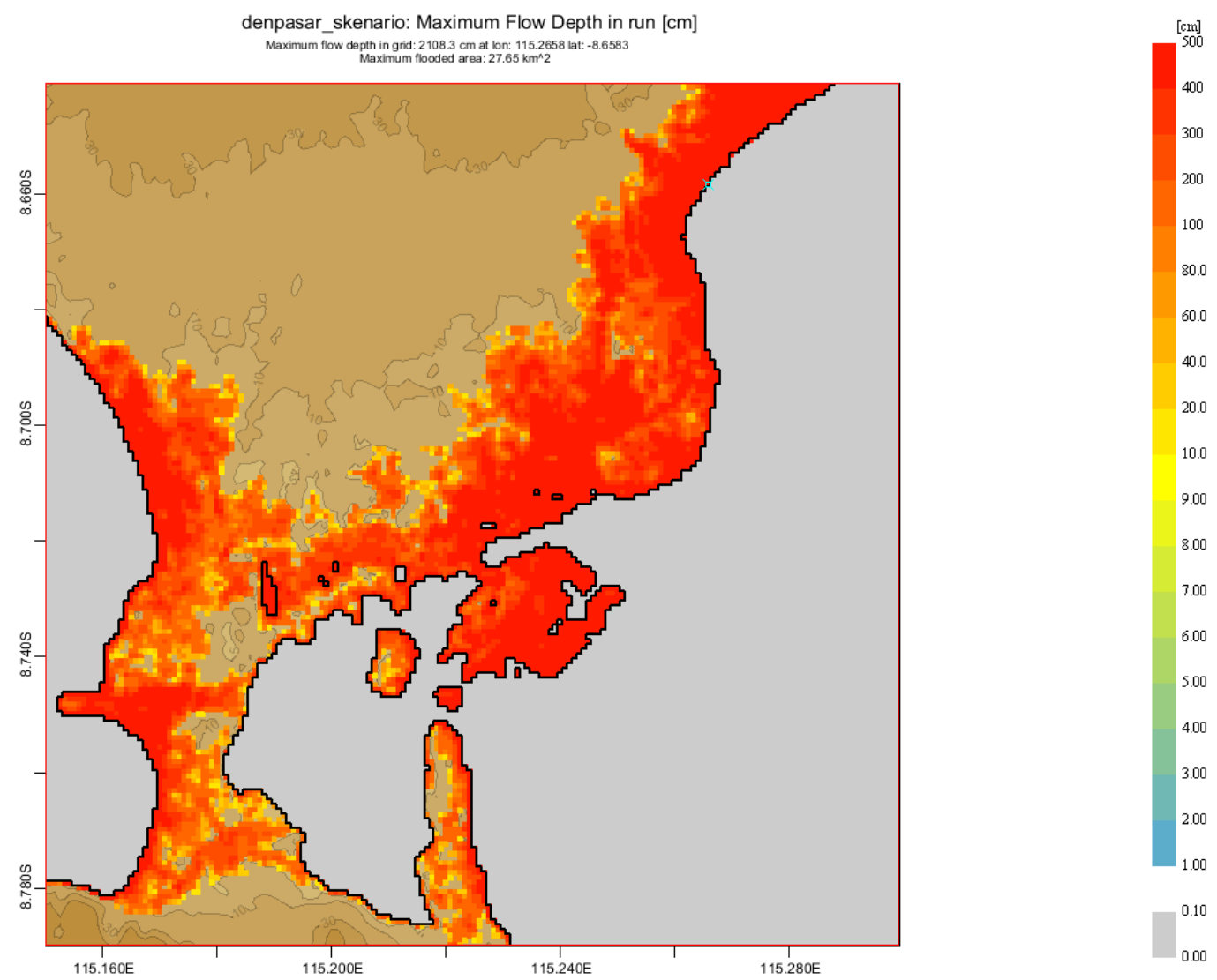

Gambar 8. Peta genangan tsunami wilayah Denpasar hasil komposit antara tsunami Banyuwangi dan skenario gempabumi Mmax 9,0 di selatan Bali

Sanur memiliki potesi lamun yang tumbuh di hamparan pantai sepanjang sekitar $8 \mathrm{~km}$ yang terbentang dari Pantai Sanur sampai Mertasari. Substrat dasar tempat lamun itu tumbuh terdiri atas pasir, pecahan karang, karang mati,batuan massif, karang dan algae (Graha, Arthana, dan Karang, 2016). Keberadaan lamun ini membuat ombak wilayah Sanur berpasir putih lebih tenang dibandingkan dengan yang berpasir hitam. Hal ini pula yang membuat ketinggian tsunami lebih tinggi di bagian utara yang berpasir hitam. Untuk itu keberadaan lamun ini harus tetap dilestarikan selain menyeimbangkan ekosistem juga mengurangi dampak tsunami. Daun lamun yang lebat akan memperlambat aliran air yang disebabkan oleh arus dan ombak, sehingga perairan di sekitarnya menjadi tenang. Selain itu, rimpang dan akar lamun dapat menahan dan mengikat sedimen, sehingga dapat menguatkan dan menstabilkan dasar permukaan. Daun lamun yang berfungsi sebagai penangkap sedimen serta penahan arus dan gelombang yang berperan dalam mencegah erosi pantai (Sjafrie, dkk., 2018).

Sanur sudah memiliki rencana evakuasi yang baik. Evakuasi vertikal merupakan solusi karena jarak untuk mencapai daerah aman sekitar 2-3 km secara geografis belum termasuk dampak kemacetan yang ditimbulkan. Hotel dengan lantai 3 ke atas dan beberapa gedung dengan berlantai 2 di bagian barat Jalan Bypass Ngurah Rai diharapkan bisa menjadi tempat evakuasi sementara.

Rancangan peta evakuasi tsunami (Gambar 9) dibuat sebagai gambaran kasar dan perlu adanya koordinasi semua pihak dalam penyusunannya lebih lanjut terutama penyusunan zona merah dan kuning. Dalam rancangan peta evakuasi pada Gambar 9 zona merah dan kuning dibuat berdasarkan pada potensi ketinggian maksimum genangan inundasi tsunami pada skenario terburuk. Peta masih dibuat menggunakan standar topografi dan bathimetri saja, belum memperhatikan kemudahan dalam melakukan evakuasi walaupun sudah berisi jalur dan objek vital yang rentan dan tempat untuk evakuasi sementara.

Hal ini perlu disesuaikan agar memudahkan dalam menentukan daerah merah dan kuning dalam evakuasi. BPBD baik kota maupun provinsi memiliki peran penting dalam mengawali proses penyusunan peta evakuasi tsunami yang baru. 


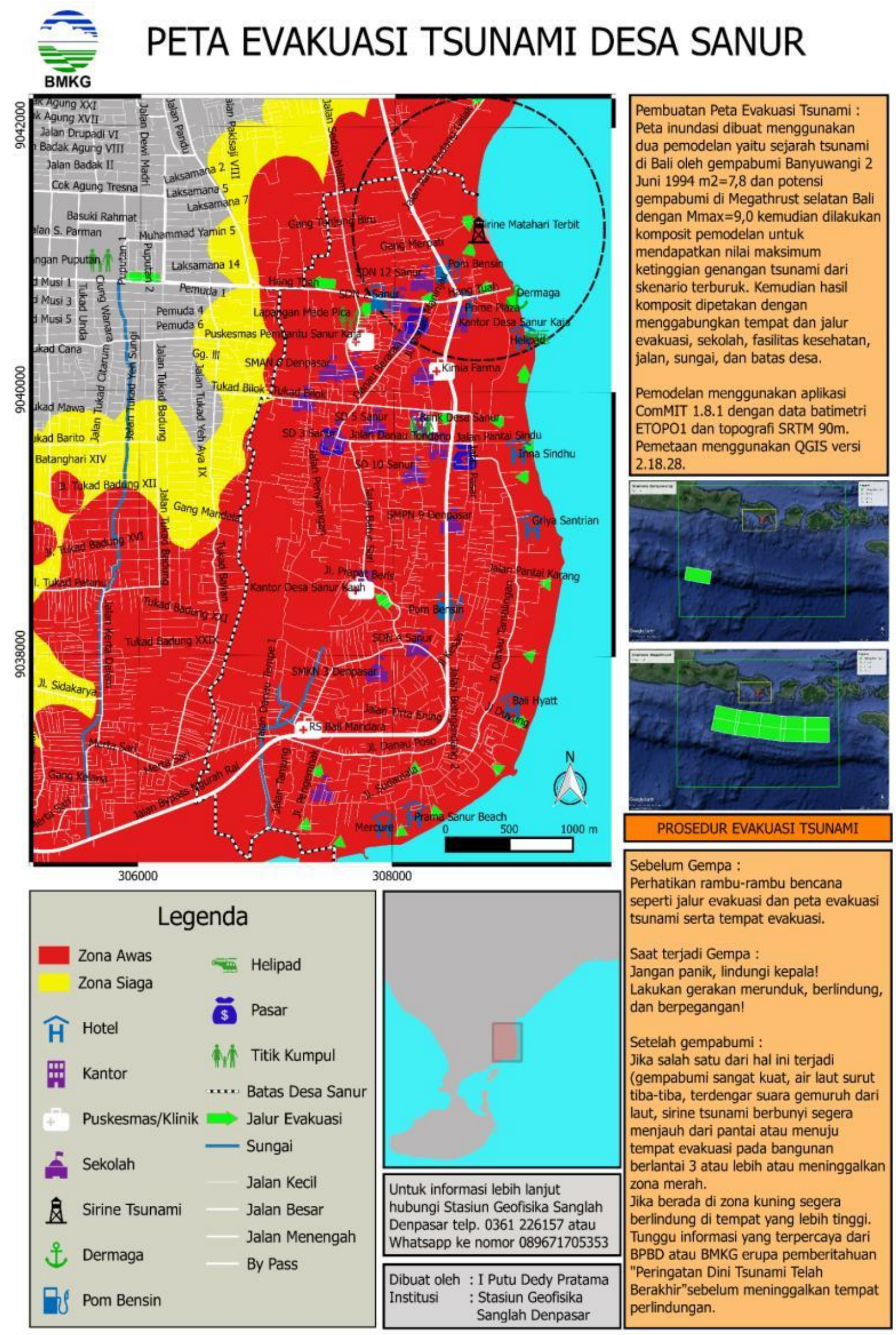

Gambar 9. Rancangan peta evakuasi tsunami wilayah Sanur 


\section{Simpulan dan saran}

Berdasarkan analisis pemodelan inundasi tsunami diperoleh hasil jarak inundasi bervariasi antara 2-3 km ke arah darat. Ketinggian tsunami di pantai bervariasi antara 9,9 hingga 16,8 meter dengan run-up maksimum 21 meter, dan waktu tiba tsunami di pantai sekitar 24 menit setelah gempabumi terjadi. Skenario tsunami dengan skenario terburuk menghasilkan ketinggian tsunami tertinggi justru terjadi di bagian utara Sanur. Hal ini karena bentuk pantai di utara berupa teluk sehingga gelombang tsunami mengalami amplifikasi.

Peta evakuasi tsunami merupakan hal penting dalam mitigasi tsunami. Keseluruhan pesisir pantai Denpasar merupakan daerah dengan dampak tsunami pada level awas $(\mathrm{h}>3$ meter) perlu menjadi perhatian agar rencana evakuasi dibuat dengan baik dan diketahui oleh penduduk setempat maupun wisatawan.

Diperlukan adanya kajian terbaru terkait peta evakuasi tsunami yang sudah ada mengingat adanya pemutakhiran potensi gempabumi sesuai dengan PuSGeN 2017 dan sosialisasi terkait evakuasi tsunami ke daerah-daerah di wilayah Bali yang berpotensi.

Untuk itu perlu ada permutakhiran peta evakuasi tsunami dan rancangan rencana evakuasi yang melibatkan berbagai pihak. Kerja sama antara BPBD Kota Denpasar dan BMKG Stasiun Geofisika Denpasar khususnya dalam peta evakuasi tsunami dan sosialisasinya perlu ditingkatkan. Penelitian ini dapat menjadi perintis permutahiran peta evakuasi tsunami di wilayah Sanur.

\section{Daftar Rujukan}

Amante, C. dan B.W. Eakins, 2009. ETOP01 1 Arc-Minute Global Relief Model: Procedures, Data Sources and Analysis. NOAA Technical Memorandum NESDIS NGDC-24. National Geophysical Data Center, NOAA. doi:10.7289/V5C8276M [diakses 1 Januari 2020].

Aperus, R., Pujiastuti, D., dan Billiyanto, R. 2016. Pemodelan Tinggi dan Waktu Tempuh Gelombang Tsunami Berdasarkan Data Historis Gempa Bumi Bengkulu 4 Juni 2000 di Pesisir Pantai Bengkulu. Jurnal Fisika Unand Vol. 5, No. 4. ISSN 2302-8491.

Courant, R., Friedrichs, K., dan Lewy, H. 1967. "On the partial difference equations of mathematical physics,"IBM Journal of Research and Development, 11 (2): 215-234.

Delavar, M. R., Mohammadi, H., Sharifi, M. A., dam Pirooz, M. D. 2017. Tsunami risk assessment modelling in Chabahar Port, Iran. The International Archives of the Photogrammetry, Remote Sensing and Spatial Information Sciences, Volume XLII-2/W7, ISPRS Geospatial Week .

Global CMT. Internet: www.globalcmt.org/CMTsearch.html, diakses 1 Januari 2020.

Graha, Y. I., Arthana, I W., dan Astawa Karang, I W. G. 2016. Simpanan Karbon Padang Lamun di Kawasan Pantai Sanur, Kota Denpasar. Ecotrophic : Jurnal Ilmu Lingkungan OJournal of Environmental Science), [S.l.], v. 10, n. 1, p. 46-53. ISSN 1907-5626.

Kelompok Kerja Perencanaan Evakuasi Untuk Sanur. 2010. Rencana Evakuasi Tsunami untuk Sanur, Bali. Denpasar : Kerjasama Pemerintah Kota Denpasar dan GTZ IS - GITEWS.

Nelson, A. Jarvis, 2007, An evaluation of void filling interpolation methods for SRTM data, International Journal of Geographic Information Science, 21:9, 983-1008.

Nurfitriani, Mamuaya, G. E., Djamaluddin, R., dan Yatimantoro, T. 2018. Analisis Potensi Rambatan Tsunami Di Pantai Utara Desa Dulukapa Dan Deme 1 Kabupaten Gorontalo Utara Untuk Mitigasi Bencana Tsunami. Majalah Ilmiah Globe Vol. 20 No. 2 Hal. 67-76. http://dx.doi.org/10.24895/MIG.2018.20-2.767

Purnama, A. A. D. S., Paramarta, I. B. A., dan Rahman, M. S. S. 2019. Estimasi Run Updan Waktu Tiba Tsunami di Daerah Bali Berdasarkan Simulasi TOAST. Buletin Fisika Vol. 20 No. 1. https://doi.org/10.24843/BF.2019.v20.i01

Tim Pusat Gempabumi dan Tsunami. 2019. Katalog Tsunami Indonesia Tahun 416-2018. Jakarta : Badan Meteorologi Klimatologi dan Geofisika. ISBN 972-602-52407-0-6

Tim Pusat Studi Gempa Nasional. 2017. Peta Sumber dan Bahaya Gempa Indonesia Tahun 2017. Jakarta : Kementrian Pekerjaan Umum dan Perumahan Rakyat

Titov, V. V., Moore, C. W., Greenslade, D. J. M., Pattiaratchi, C., Badal, R., Synolakis, C. E., \& Kânoğlu, U. 2011. A new tool for inundation modeling: Community Modeling Interface for Tsunamis (ComMIT). Pure and Applied Geophysics, 168(11), 2121-2131. https://doi.org/10.1007/s00024$\underline{011-0292-4}$

Sjafrie, N. D. M., dkk. 2018. Status Padang Lamun Indonesia 2018 Ver. 02. Jakarta : Puslit Oseanografi LIPI. ISBN 978-602-650-420-3.

UNIDATA. Internet https://www.unidata.ucar.edu/software/netcdf/. Diakses 31 Desember 2019. 
Wahyu, R. O., Djamaluddin, R., Mamuaya, G. E., Yatimantoro, T., dan Priyobudi. 2018. Pemodelan Inundasi Tsunami di Sepanjang Pesisir Kota Manado akibat Gempabumi M8,5 di Zona Subduksi Sulawesi Utara. Jurnal Meteorologi dan Geofisika, Vol. 19 No. 1, hal. 13-18. http://dx.doi.org/10.31172/jmg.v19i1.448

Widiyani, D, M. S. 2014. PERKEMBANGAN DAERAH PARIWISATA SANUR (Dilihat dari Teori Lokasi Growth Pole). Anala Vol. 1. No. 11. 